\title{
PENDUGAAN BOBOT BADAN CALON PEJANTAN SAPI BALI MENGGUNAKAN DIMENSI UKURAN TUBUH
}

\section{THE ESTIMATION OF BODY WEIGHT OF BULLS CANDIDATE OF BALI CATTLE USING SOME BODY DIMENSION}

\author{
Nani Zurahmah* dan Enos The \\ Jurusan Penyuluhan Peternakan, Sekolah Tinggi Penyuluhan Pertanian, Jl. SPMA, Reremi, Manokwari, Papua Barat
}

\section{INTISARI}

Penelitian bertujuan untuk menemukan penduga terbaik bagi bobot badan (BB) calon pejantan (jantan muda) sapi Bali dari dimensi ukuran tubuhnya: lingkar dada (LD), panjang badan (PB) dan tinggi badannya (TB). Tiga puluh satu calon pejantan sapi Bali (umur 1,5 sampai 2 tahun) digunakan dalam penelitian ini. Analisis Best Subsets Regression digunakan untuk menemukan model pendugaan bobot badan terbaik bagi calon pejantan sapi Bali. Hasil penelitian menunjukkan bahwa lingkar dada merupakan penduga bobot badan terbaik bagi calon pejantan sapi Bali bila pendugaan dilakukan hanya menggunakan satu peubah bebas, melalui formula: $\mathrm{BB}=2,62 \mathrm{LD}-192$. Bila pendugaan bobot badan tersebut menggunakan dua peubah bebas, maka lingkar dada dan panjang badan calon pejantan sapi Bali merupakan penduga terbaik, melalui formula: $\mathrm{BB}=2,36 \mathrm{LD}+0,78 \mathrm{~PB}-236$. Pendugaan bobot badan calon pejantan sapi Bali umur 1,5 sampai 2 tahun menggunakan tiga peubah bebas (LD, PB, dan TB), dapat dilakukan menggunakan formula berikut: $\mathrm{BB}=2,30 \mathrm{LD}+0,733 \mathrm{~PB}+0,139 \mathrm{~TB}-237$, namun akan jauh lebih efisien dan efektif bila pendugaan bobot badan tersebut menggunakan formula: $\mathrm{BB}=2,36 \mathrm{LD}+0,78 \mathrm{~PB}-236$, karena tingkat akurasi formula tersebut lebih baik. Formula-formula tersebut sangat baik diaplikasikan pada peternakan tradisional di suatu wilayah dalam rangka memilih calon pejantan yang baik untuk wilayah tersebut.

(Kata kunci: Calon pejantan sapi Bali, Bobot badan, Dimensi ukuran tubuh)

\section{ABSTRACT}

This study aims to find the best estimation of body weight (BB) of Bali bulls candidates (young male) by body dimensions: chest circle (LD), body length (PB) and body height (TB). Thirty-one bulls candidates for Bali cattle (age of 1.5 to 2 years) used in this study. Best Subsets Regression analysis was used to find the best of body weight estimation model for bull candidate of Bali cattle. The results showed that the chest circle was the best predictor of body weight for bulls candidates when estimating performance using only one independent variable, by the formula: $B B$ $=2.62 \mathrm{LD}-192$. When estimating the body weight using two independent variables, then the chest circle and body length of bulls candidates for Bali cattle was the best predictor, by the formula: $B B=2.36 L D+0.78 P B-236$. The body weight estimation of bulls candidate of Bali cattle (age of 1,5 to 2 years) using the three independent variables ( $L D, P B$, and TB), could be done using the formula: $B B=2.30 L D 0.7330 .139$ TB PB - 237, but it would be much more efficient and effective when estimating the body weight using the formula: $B B=2.36 L D+0.78 P B-236$, because the accuracy rate was higher formula. Formulas are very well applied to traditional farming in a region in order to choose a good bulls candidates of Bali cattle for the region.

(Keywords: Bulls candidate of Bali cattle, Body weight, Body dimensions)

\section{Pendahuluan}

Dalam rangka menyongsong Swasembada Daging pada tahun 2014, upaya pengembangan sapi potong dari berbagai aspek perlu dilakukan, terutama sapi potong asli maupun lokal Indonesia. Salah satu aspek penting dan mendesak untuk dikerjakan adalah aspek peningkatan mutu genetik

\footnotetext{
* Korespondensi (corresponding author):

Telp. +62 85244340538

E-mail: znanizurahmah@yahoo.co.id
}

sapi potong. Aspek ini penting dilakukan dalam rangka terbentuknya populasi sapi potong dalam negeri yang produktif sehingga mampu memenuhi kebutuhan daging dalam negeri. Populasi demikian akan terbentuk manakala ada upaya pengembangan pembibitan sapi potong secara berkelanjutan.

Teori dasar dalam peningkatan mutu genetik ternak sapi potong adalah perkawinan antara induk yang baik dengan pejantan yang baik dapat diharapkan akan menghasilkan anak yang baik pula. Sehubungan dengan teori tersebut maka pemilihan calon tetua, khususnya calon pejantan menjadi 
sangat penting dalam rangka menghasilkan keturunan yang produktif. Kriteria untuk memperoleh calon pejantan yang baik pada sapi Bali, selain harus memperhatikan kemurnian bangsa sapi Bali, libido dan kualitas sperma, kriteria bobot badan calon pejantan pada umur 2 tahun merupakan kriteria penting yang harus diperhatikan pula (Anonimus, 1983). Bobot badan calon pejantan sapi Bali harus berada di atas rata-rata bobot badan dari generasinya pada suatu wilayah tertentu.

Bobot badan seekor sapi hanya dapat diketahui secara tepat melalui cara penimbangan, namun dalam situasi dan kondisi tertentu, terutama pada kondisi peternakan rakyat, jarang atau tidak tersedia alat timbangan ternak sapi. Oleh karena itu dibutuhkan cara lain yang dianggap praktis untuk mengestimasi bobot badan seekor ternak. Beberapa penelitian telah melaporkan adanya hubungan antara dimensi ukuran tubuh pada sapi dengan bobot badannya, sehingga dihasilkan suatu formula untuk mengestimasi bobot badan pada umur dan jenis kelamin tertentu (Sumadi et al., 2001; Maskyadji, 1997; Clufran, 1976; Saleh, 1982). Francis et al. (2002) juga telah membuktikan adanya korelasi yang kuat dan positif antara bobot badan dengan panjang badan $(\mathrm{r}=0,90)$ maupun dengan lingkar dada $(r=0,96)$ pada sapi yang diteliti. Hasil penelitian ini menunjukkan bahwa dimensi ukuran tubuh dapat digunakan untuk mengestimasi bobot badan pada sapi.

Menurut Gafar (2007), hingga kini telah dikenal beberapa formula untuk mengestimasi bobot badan pada sapi, yaitu formula dari Schoorl [Bobot badan $\left.(\mathrm{lbs})=(\text { Lingkar dada }(\mathrm{cm})+22)^{2} / 100\right]$, Winter $\left[\right.$ Bobot badan ${ }_{(\text {lbs })}=\left\{\left(\text { Lingkar dada } a_{(\text {inchi })}\right)^{2} \mathrm{x}\right.$ Panjang $\left.\left.\operatorname{badan}_{(\text {inchi) }}\right\} / 300\right]$, dan Smith [Bobot badan $\left._{(\mathrm{lbs})}=\left\{\text { Lingkar } \operatorname{dada}_{(\mathrm{cm})}+18\right\}^{2} / 100\right]$. Namun demikian, formula-formula tersebut belum tentu tepat untuk menduga bobot badan pada semua bangsa sapi. Akbar (2008) telah mencoba mengaplikasikan formula-formula di atas untuk sapi-sapi lokal Indonesia, namun menghasilkan bias yang tinggi. Oleh karena itu, formula untuk estimasi bobot badan baik pada bangsa sapi asli maupun sapi lokal Indonesia perlu dibuat tersendiri berdasarkan jenis kelamin dan kelompok umur. Tujuan penelitian adalah menemukan formula untuk mengestimasi bobot badan calon pejantan sapi Bali (umur 1,5 sampai 2 tahun) berdasarkan dimensi ukuran tubuh (panjang badan, lingkar dada, dan tinggi badan).

\section{Materi dan Metode}

Penelitian menggunakan materi berupa 31 data bobot badan dan dimensi ukuran tubuh (panjang badan, lingkar dada, dan tinggi badan) sapi
Bali jantan umur 1,5 sampai 2 tahun. Data tersebut diperoleh dari rekording (tahun 2004) yang tersedia di Balai Pembibitan Ternak Unggul (BPTU) Sapi Bali, berlokasi di desa Pangyangan, kecamatan Pulukan, kabupaten Jembrana, provinsi Bali.

Adapun data bobot badan dan dimensi ukuran tubuh sapi Bali penelitian diperoleh dengan cara sebagai berikut: (1) data bobot badan ( $\mathrm{kg}$ ) diperoleh dengan cara menimbang bobot hidup menggunakan timbangan digital berkapasitas $1.000 \mathrm{~kg}$; (2) data panjang badan $(\mathrm{cm})$ diperoleh dengan cara mengukur jarak antara sendi bahu (later tuberosity of humerus) sampai ke tepi belakang tulang pelvis dengan menggunakan tongkat ukur; (3) data tinggi badan $(\mathrm{cm})$ diperoleh dengan cara mengukur menggunakan tongkat ukur dari bagian pundak ke permukaan tanah mengikuti garis tegak lurus; dan (4) data lingkar dada $(\mathrm{cm})$ diperoleh dengan cara melingkarkan pita ukur mengikuti lingkar dada atau tubuh di belakang bahu. Data umur sapi Bali penelitian diperoleh dengan mencatat tanggal kelahirannya pada rekording yang tersedia.

Data bobot badan dan dimensi ukuran tubuh sapi Bali penelitian yang diperoleh dilakukan analisis deskriptif untuk memperoleh gambaran tentang rerata, salah baku, nilai minimum, nilai maksimum dan koefisien keragaman dari peubahpeubah tersebut. Formula untuk estimasi bobot badan $(\mathrm{kg})$ calon pejantan sapi Bali menggunakan: (a) satu peubah bebas (lingkar dada, panjang badan, atau tinggi badan); (b) dua peubah bebas (lingkar dada dan panjang badan, lingkar dada dan tinggi badan, atau panjang badan dan tinggi badan); dan (c) tiga peubah bebas (lingkar dada dan panjang badan serta tinggi badan), diperoleh melalui analisis Best Subset Regression dengan bantuan paket program statistika: MINITAB Release 13.20 for Windows. Pemilihan formula terbaik, baik dalam jumlah peubah bebas yang sama maupun antar jumlah peubah bebas, didasarkan atas nilai $\mathrm{R}^{2}, \mathrm{C}-\mathrm{p}$, dan s. Formula terbaik adalah yang memiliki nilai $\mathrm{R}^{2}$ tertinggi, nilai $\mathrm{C}-\mathrm{p}$ terkecil dan nilai s terkecil.

\section{Hasil dan Pembahasan}

\section{Performan bobot badan dan dimensi ukuran tubuh}

Tabel 1 menyajikan hasil analisis statistik deskriptif terhadap data bobot badan dan dimensi ukuran tubuh (lingkar dada, panjang badan, dan tinggi badan) calon pejantan sapi Bali pada kisaran umur 1,5 sampai 2 tahun yang digunakan dalam penelitian ini.

Pada Tabel 1 terlihat bahwa koefisien keragaman pada peubah bobot badan lebih tinggi dibandingkan peubah-peubah dimensi ukuran tubuh calon pejantan sapi Bali penelitian. Hal ini 
Tabel 1. Deskripsi bobot badan dan dimensi ukuran tubuh calon pejantan sapi Bali (description of body weight and some body dimension in bull candidates of Bali cattle)

\begin{tabular}{lcccrrr}
\hline \hline \multicolumn{1}{c}{ Peubah (variable) } & $\mathrm{n}$ & $\begin{array}{c}\text { Rataan } \\
\text { (average) }\end{array}$ & $\begin{array}{c}\text { Salah baku (standard of } \\
\text { deviation) }\end{array}$ & $\begin{array}{c}\text { Minimum } \\
\text { (minimum) }\end{array}$ & $\begin{array}{c}\text { Maksimum } \\
\text { (maximum) }\end{array}$ & $\begin{array}{c}\text { KK }(C V) \\
(\%)\end{array}$ \\
\hline Bobot badan (body weight) & 31 & 170,84 & 20,52 & 131,00 & 209,00 & 12,01 \\
Panjang badan (body lenght) & 31 & 100,23 & 5,15 & 86,00 & 110,00 & 5,14 \\
Tinggi badan (body height) & 31 & 106,97 & 4,93 & 90,00 & 117,00 & 4,61 \\
Lingkar dada (chest circle) & 31 & 138,84 & 6,82 & 121,00 & 151,00 & 4,91 \\
\hline
\end{tabular}

KK: koefisien keragaman ( $C V$ : coeficient of variance).

menunjukkan bahwa pertumbuhan bobot badan lebih variatif dibandingkan dimensi ukuran tubuh sapi penelitian.

Pemerintah telah menetapkan bobot badan, panjang badan, tinggi badan (tinggi pundak atau tinggi gumba) dan lingkar dada sebagai ukuran statistik vital yang dijadikan sebagai kriteria pemilihan bibit sapi potong di Indonesia. Adapun ukuran statistik vital untuk calon pejantan sapi Bali (sapi jantan muda, umur 1,5 sampai 2 tahun), ditetapkan sebagai berikut: bobot badan $222 \mathrm{~kg}$, panjang badan $122 \mathrm{~cm}$, tinggi badan $110 \mathrm{~cm}$, dan lingkar dada $172 \mathrm{~cm}$ (Anonimus, 1983). Bila ukuran statistik vital yang ditetapkan pemerintah ini dibandingkan dengan ukuran statistik vital yang ditemukan pada penelitian ini, maka dapat terlihat bahwa calon-calon pejantan sapi Bali (umur 1,5 sampai 2 tahun) di wilayah penelitian masih berada di bawah standar ukuran statistik vital yang ditetapkan pemerintah. Bila hasil penelitian ini dibandingkan dengan hasil penelitian Djagra et al. (2002) terhadap sapi Bali di provinsi Bali, dan juga dengan hasil penelitian Laya (2005) terhadap sapi Bali di provinsi Gorontalo, maka angka-angka dari ukuran statistik vital sapi Bali di wilayah penelitian ini tidak terlalu berbeda jauh.

Selain standar ukuran statistik vital sapi Bali yang ditetapkan pemerintah, maka pada tahun 2006, pemerintah melalui Peraturan Menteri Pertanian Nomor: 54/Permentan/OT.140/10/2006 juga telah menetapkan standar mutu bibit sapi Bali (Anonimus, 2006), dimana sapi Bali jantan (umur 2 sampai 3 tahun) secara kualitatif harus memiliki syarat sebagai berikut: warna bulu hitam, lutut ke bawah berwarna putih, pantat warna putih berbentuk setengah bulan, ujung ekor berwarna hitam, tanduk tumbuh baik dan warna hitam, bentuk kepala lebar, leher kompak dan kuat. Secara kuantitatif, standar mutu sapi Bali jantan (umur 2 sampai 3 tahun) dibedakan menjadi tiga kelas: kelas I apabila memiliki tinggi badan (gumba) minimal $119 \mathrm{~cm}$ dan panjang badan minimal $121 \mathrm{~cm}$; kelas II apabila memiliki tinggi badan (gumba) minimal $111 \mathrm{~cm}$ dan panjang badan minimal $110 \mathrm{~cm}$; kelas III apabila memiliki tinggi badan (gumba) minimal $108 \mathrm{~cm}$ dan panjang badan minimal $106 \mathrm{~cm}$. Berdasarkan standar mutu bibit sapi Bali di atas, maka caloncalon pejantan sapi Bali penelitian kurang lebih dapat digolongkan ke dalam bibit kelas III.

Berdasarkan hasil penilaian terhadap ukuran statistik vital maupun mutu bibit pada calon pejantan sapi Bali yang terdapat di BPTU Sapi Bali, maka tampaknya kerja keras perlu dilakukan guna meningkatkan performans agar dapat mencapai standar yang ditetapkan pemerintah tersebut.

\section{Hubungan bobot badan dengan dimensi ukuran tubuh}

Tabel 2 menyajikan hasil analisis hubungan antara bobot badan sebagai peubah respon dan dimensi ukuran tubuh, yaitu panjang badan, tinggi badan dan lingkar dada, sebagai peubah bebas dari calon pejantan sapi Bali (umur 1,5 sampai 2 tahun) yang dianalisis dengan menggunakan Best Subset Regression.

Pada Tabel 2 terlihat bahwa bila bobot badan calon pejantan sapi Bali diduga menggunakan salah satu peubah bebas dari tiga peubah bebas yang diteliti, maka ukuran lingkar dada merupakan penduga terbaik bobot badannya, karena pendugaan tersebut memiliki nilai $\mathrm{R}^{2}$ terbesar $(75,5 \%)$, nilai $\mathrm{C}$ $\mathrm{p}$ terkecil $(4,0)$ dan $\mathrm{s}$ terkecil $(10,3)$ dibandingkan bila menggunakan peubah bebas lainnya (ukuran panjang badannya maupun tinggi badannya). Pendugaan bobot badan (BB) calon pejantan sapi Bali tersebut bila menggunakan lingkar dadanya (LD) dapat dilakukan menggunakan formula berikut: $\mathrm{BB}=2,62 \mathrm{LD}-192$. Hasil analisis variansi menunjukkan bahwa formula tersebut sangat signifikan $(\mathrm{P}<0,01)$ bila digunakan sebagai penduga bobot badan calon pejantan sapi Bali umur 1,5 sampai 2 tahun.

Bila bobot badan calon pejantan sapi Bali tersebut diduga menggunakan dua peubah bebas di antara tiga peubah bebas yang diteliti, maka ukuran lingkar dada dan panjang badannya merupakan penduga bobot badan terbaik (nilai $\mathrm{R}^{2}$ terbesar $=$ 78,6\%; serta nilai C-p dan s terkecil, masing-masing 2,0 dan 9,8) dibandingkan ukuran lingkar dada dan tinggi badan maupun ukuran panjang badan 
Tabel 2. Hasil analisis Best Subsets Regression antara bobot badan dengan lingkar dada, panjang badan dan tinggi badan pada calon pejantan sapi Bali (results of Best Subsets Regression analysis between body weight with chest circle, body lenght, and body height in bull candidates of Bali cattle)

\begin{tabular}{|c|c|c|c|c|c|c|}
\hline \multirow[b]{2}{*}{$\begin{array}{c}\text { Jumlah peubah bebas (the number of } \\
\text { independent variabel) }\end{array}$} & \multirow[b]{2}{*}{$\mathrm{R}^{2}$} & \multirow[b]{2}{*}{ C-p } & \multirow[b]{2}{*}{$\mathrm{s}$} & \multicolumn{3}{|c|}{ Dimensi ukuran tubuh (body dimension) } \\
\hline & & & & $\begin{array}{l}\text { Lingkar dada } \\
\text { (chest circle) }\end{array}$ & $\begin{array}{l}\text { Panjang badan } \\
\text { (body lenght) }\end{array}$ & $\begin{array}{l}\text { Tinggi badan } \\
\text { (body height })\end{array}$ \\
\hline 1 & 75,5 & 4,0 & 10,3 & $\mathrm{X}$ & & \\
\hline 1 & 53,1 & 32,3 & 14,3 & & $\mathrm{X}$ & \\
\hline 1 & 28,2 & 63,9 & 17,7 & & & $\mathrm{X}$ \\
\hline 2 & 78,6 & 2,0 & 9,8 & $\mathrm{X}$ & $\mathrm{X}$ & \\
\hline 2 & 76,6 & 4,7 & 10,3 & $\mathrm{X}$ & & $\mathrm{X}$ \\
\hline 2 & 54,2 & 32,9 & 14,4 & & $\mathrm{X}$ & $\mathrm{X}$ \\
\hline 3 & 78,7 & 4,0 & 10,0 & $\mathrm{X}$ & $\mathrm{X}$ & $\mathrm{X}$ \\
\hline
\end{tabular}

$\mathrm{X}$ : Variabel bebas yang dilibatkan dalam formula (the independent variable which used in model).

dan tinggi badannya. Pendugaan bobot badan (BB) calon pejantan sapi Bali tersebut bila menggunakan lingkar dadanya (LD) dan panjang badannya (PB) dapat menggunakan formula berikut: $\mathrm{BB}=2,36 \mathrm{LD}$ $+0,78 \mathrm{~PB}-236$. Hasil analisis variansi menunjukkan pula bahwa formula tersebut sangat signifikan $(\mathrm{P}<0,01)$ bila digunakan sebagai penduga bobot badan calon pejantan sapi Bali umur 1,5 sampai 2 tahun.

Pendugaan bobot badan (BB) calon pejantan sapi Bali umur 1,5 sampai 2 tahun menggunakan tiga peubah bebas $(\mathrm{LD}=$ lingkar dada, $\mathrm{PB}=$ panjang badan, $\mathrm{TB}=$ tinggi badan), dapat dilakukan menggunakan formula berikut: $\mathrm{BB}=2,30 \mathrm{LD}+$ $0,733 \mathrm{~PB}+0,139 \mathrm{~TB}-237$, namun akurasi dari formula ini $\left(\mathrm{R}^{2}=78,7 \%, \mathrm{C}-\mathrm{p}=4,0\right.$ dan $\left.\mathrm{s}=10,0\right)$ lebih rendah dibandingkan bila pendugaan bobot badan tersebut menggunakan lingkar dada (LD) dan panjang badan (PB) melalui formula berikut: $\mathrm{BB}=$ $2,36 \mathrm{LD}+0,78 \mathrm{~PB}-236$, karena formula yang disebut terakhir ini tingkat akurasinya lebih tinggi $\left(\mathrm{R}^{2}=78,6 \%\right.$; $\mathrm{C}-\mathrm{p}=2,0$ dan $\left.\mathrm{s}=9,8\right)$. Jadi, aplikasi pendugaan bobot badan (BB) calon pejantan sapi Bali umur 1,5 sampai 2 tahun di lapangan jauh lebih efektif dan efisien bila menggunakan dua peubah bebas, yaitu lingkar dada (LD) dan tinggi badan (TB) melalui formula: $\mathrm{BB}=2,36 \mathrm{LD}+0,78 \mathrm{~PB}-$ 236. Formula ini telah teruji signifikansinya untuk menduga bobot badan dan dapat digunakan di lapangan sebagai alat pengganti timbangan untuk mendapatkan data bobot badan jantan-jantan muda dalam rangka memilih calon-calon pejantan sapi Bali umur 1,5 sampai 2 tahun. Berdasarkan formula terbaik yang ditemukan ini, diketahui bahwa bobot badan calon pejantan sapi Bali (umur 1,5 sampai 2 tahun) sangat ditentukan oleh lingkar dada dan panjang badannya. Bila bobot badan calon pejantan kita analogkan bagaikan volume sebuah silinder, maka lingkar dada dan panjang badan calon pajantan sapi Bali tersebut dapat dianalogkan pula berturut-turut sebagai keliling lingkaran dan tinggi silinder. Jadi, semakin besar nilai lingkaran silinder dan tinggi silinder, maka volume silinder akan semakin besar pula. Hal yang sama berlaku pula bagi calon pejantan sapi Bali, dimana semakin besar nilai lingkar dada dan panjang badan, maka semakin tinggi pula nilai bobot badannya.

Dengan ditemukannya formula ini maka diharapkan pemilihan calon-calon pejantan unggul berdasarkan kriteria bobot badan (umur 1,5 sampai 2 tahun) dapat diaplikasikan pada tingkat peternakan rakyat sehingga secara berangsur-angsur akan terjadi peningkatan mutu genetik sapi Bali di berbagai wilayah di Indonesia, dan pada akhirnya swasembada daging di Indonesia dapat tercapai. Hal ini sesuai pernyataan Hardjosubroto (1994) dan Warwick et al. (1983) bahwa seleksi pada sapi Bali yang diarahkan untuk perbaikan pertumbuhannya dapat dilakukan melalui pemilihan calon-calon tetua (seleksi calon pejantan atau seleksi calon induk).

\section{Kesimpulan}

Berdasarkan hasil penelitian disimpulkan bahwa lingkar dada (LD) dan panjang badan (PB) calon pejantan sapi Bali umur 1,5 sampai 2 tahun merupakan penduga terbaik bobot badannya (BB) melalui formula: $\mathrm{BB}=2,36 \mathrm{LD}+0,78 \mathrm{~PB}-236$. Dengan demikian, formula tersebut dapat difungsikan sebagai pengganti alat timbangan bobot badan khusus untuk calon-calon pejantan sapi Bali umur 1,5 sampai 2 tahun.

\section{Daftar Pustaka}

Anonimus. 1983. Pembinaan Sumber Bibit Sapi Bali. Direktorat Jenderal Peternakan, Departemen Pertanian, Republik Indonesia, Jakarta.

Anonimus. 2006. Peraturan Menteri Pertanian Nomor 54/Permentan/OT.140/10/2006 tentang Pedoman Pembibitan Sapi Potong yang Baik (Good Breeding Practice). 
Kementerian Pertanian Republik Indonesia, Jakarta.

Akbar, M. 2008. Pendugaan bobot badan sapi persilangan Limousin berdasarkan panjang badan dan lingkar dada. Skripsi, Fakultas Peternakan, Universitas Brawijaya, Malang.

Clufran. 1976. Korelasi antara berat hidup dengan lingkar dada, panjang badan dan tinggi gumba sapi Bali kualitas ekspor asal Lombok, Nusa Tenggara Barat. Skripsi, Fakultas Peternakan, Universitas Gadjah Mada, Yogyakarta.

Djagra, I.B., I.G.N.R. Haryana, I.G.M. Putra, I.B. Mantra, dan A.A. Oka. 2002. Ukuran standar tubuh sapi Bali bibit. Laporan Hasil Penelitian Kerjasama Bappeda Propinsi Bali dengan Fakultas Peternakan Universitas Udayana, Denpasar.

Francis, S. Sibanda, and T. Kristensen. 2002. Estimating body weight of cattle using linear body measurements. Zimbabwe Veteriner Journal. Available at www.blacwelsinergy.com. Accession date: October 24, 2005.

Gafar, S. 2007. Memilih dan memilah hewan qurban. Available at http//www. disnksumbar.org. Accession date: 17 April, 2009.
Hardjosubroto, W. 1994. Aplikasi Pemuliabiakan Ternak di Lapangan. PT. Gramedia Widiasarana Indonesia, Jakarta.

Laya, N.K. 2005. Kinerja produksi sapi Peranakan Ongole (PO) dan sapi Bali di Provinsi Gorontalo. Tesis S2. Sekolah Pascasarjana, Universitas Gadjah Mada, Yogyakarta.

Maskyadji, A.S.Z.Z. 1997. Pertumbuhan dan penentuan output sapi Madura dari Pulau Madura. Tesis, Fakultas Pasca Sarjana, Universitas Gadjah Mada, Yogyakarta.

Saleh, A.R. 1982. Korelasi antara bobot badan dengan lingkar dada, lebar dada, tinggi pundak, panjang badan dan dalam dada sapi Ongole di Pulau Sumba. Karya Ilmiah, Fakultas Peternakan, Institut Pertanian Bogor, Bogor.

Sumadi, W. Hardjosubroto, N. Ngadiyono, dan S. Prihadi. 2001. Potensi sapi potong di Kabupaten Sleman: analisis dari segi pemuliaan dan produksi daging. Laporan Penelitian. Fakultas Peternakan, Universitas Gadjah Mada, Yogyakarta.

Warwick, E.J., J.M. Astuti, dan W. Hardjosubroto, 1983. Pemuliaan Ternak. Gadjah Mada University Press, Yogyakarta. 